\title{
ANALISIS EFEKTIVITAS PENGGUNAAN PORTAL RESMI MERDEKA BELAJAR KAMPUS MERDEKA MENGGUNAKAN MODEL DELONE AND MCLEAN
}

\author{
Anik Hanifatul Azizah $\varpi^{1)}$, Sandfreni $\left(^{2)}\right.$, dan Muhammad Bahrul Ulum $\varpi^{3)}$ \\ ${ }^{1,2}$ Sistem Informasi, Universitas Esa Unggul \\ ${ }^{3}$ Teknik Informatika, Universitas Esa Unggul \\ 1,2,3 Jl.Arjuna Utara No.9, Duri Kepa, Kec. Kebon Jeruk, Jakarta Barat, 11510 \\ E-mail : anik.hanifa@esaunggul.ac.id ${ }^{1)}$, sandfreni@esaunggul.ac.id ${ }^{2}$, m.bahrul_ulum@esaunggul.ac.id ${ }^{3)}$
}

\begin{abstract}
ABSTRAK
Merdeka Belajar Kampus Merdeka (MBKM) merupakan program pemerintah yang telah diselenggarakan sebagai kebijakan dalam pembelajaran di Perguruan Tinggi. MBKM merupakan wujud pembelajaran di perguruan tinggi yang otonom dan fleksibel sehingga tercipta kultur belajar yang inovatif, tidak mengekang dan sesuai dengan kebutuhan mahasiswa. Untuk mendukung keberlangsungan nya, tentunya program ini juga didukung dengan sistem terintegrasi yang dirancang khusus untuk mengakomodir kegiatan MBKM. Portal resmi MBKM memuat segala informasi dan proses pelaksanaan kegiatan MBKM bagi mahasiswa, dosen maupun Universitas seluruh Indonesia. Namun sejauh ini belum terdapat data yang menyajikan tentang bagaimana efektivitas portal resmi tersebut dan hal apakah yang dapat dikembangkan berdasarkan persepsi pengguna. Penelitian ini bertujuan untuk menganalisis faktor-faktor yang mempengaruhi minat untuk menggunakan portal resmi kampus merdeka dan efektivitas penggunaan dengan menggunakan model Kesuksesan Sistem Informasi. Penelitian ini dikembangkan dengan metode kuantitatif dengan proses pengembangan variabel dan indikator-indikator dari model yang dikembangkan. Untuk mendapatkan data primer, penulis menyebarkan kuesioner kepada 136 orang responden dan melakukan analisis data menggunakan perangkat lunak SmartPLS. Hasil analisis menunjukkan bahwa sebagian besar variabel terkait dapat mempengaruhi efektivitas penggunaan sistem. Dari keseluruhan hipotesis, delapan hipotesis diterima dan menyatakan pengaruh signifikan pada model yang diteliti, serta hanya terdapat satu hipotesis yang menyatakan tidak berpengaruh signifikan, yakni kualitas layanan terhadap niat untuk menggunakan. Hal ini dapat diartikan bahwa minat pengguna untuk mengadopsi portal resmi kampus merdeka cukup besar dan efektivitas sistem masih dapat dikembangkan lagi. Implikasi dari penelitian ini relevan bagi pihak pengembang agar memperhatikan kembali faktor-faktor yang mempengaruhi minat individu dan mengetahui efektivitas sistem untuk pengembangan sistem ke depannya.
\end{abstract}

Kata Kunci: Kampus Merdeka, Adopsi Pengguna, Model Analisis, Kesuksesan Sistem, Efektivitas Sistem

\section{PENDAHULUAN}

Teknologi informasi dan komunikasi telah berkembang pesat dan memiliki peran penting dalam kehidupan masyarakat. Perkembangan teknologi yang pesat dengan penemuan-penemuan baru untuk mempermudah aktivitas manusia telah menyebabkan perubahan pada pola hidup manusia di berbagai bidang. Dalam rangka menyiapkan mahasiswa menghadapi perubahan sosial, budaya, dunia kerja dan kemajuan teknologi yang pesat, kompetensi mahasiswa harus disiapkan untuk lebih relevan dengan kebutuhan zaman (Prahani, et al., 2020). Link and match tidak saja dengan dunia industri dan dunia kerja tetapi juga dengan masa depan yang berubah dengan cepat. Perguruan Tinggi dituntut untuk dapat merancang dan melaksanakan proses pembelajaran yang inovatif agar mahasiswa dapat meraih capaian pembelajaran mencakup aspek sikap, pengetahuan, dan keterampilan secara optimal dan selalu relevan (Sudaryanto, 2020).
Kebijakan Merdeka Belajar - Kampus Merdeka diharapkan dapat menjadi jawaban atas tuntutan tersebut. Kampus Merdeka merupakan wujud pembelajaran di perguruan tinggi yang otonom dan fleksibel sehingga tercipta kultur belajar yang inovatif, tidak mengekang, dan sesuai dengan kebutuhan mahasiswa (Siregar, et al., 2020). Program utama yaitu: kemudahan pembukaan program studi baru, perubahan sistem akreditasi perguruan tinggi, kemudahan perguruan tinggi negeri menjadi PTN berbadan hukum, dan hak belajar tiga semester di luar program studi. Mahasiswa diberikan kebebasan mengambil SKS di luar program studi, tiga semester yang di maksud berupa 1 semester kesempatan mengambil mata kuliah di luar program studi dan dua semester melaksanakan aktivitas pembelajaran di luar perguruan tinggi (Fuadi \& Aswita, 2021).

Berbagai bentuk kegiatan belajar di luar perguruan tinggi, di antaranya melakukan magang/praktik kerja di Industri atau tempat kerja lainnya, melaksanakan proyek pengabdian kepada masyarakat di desa, mengajar di 
satuan pendidikan, mengikuti pertukaran mahasiswa, melakukan penelitian, melakukan kegiatan kewirausahaan, membuat studi/ proyek independen, dan mengikuti program kemanusiaan. Semua kegiatan tersebut harus dilaksanakan dengan bimbingan dari dosen. Kampus merdeka diharapkan dapat memberikan pengalaman contextual lapangan yang akan meningkatkan kompetensi mahasiswa secara utuh, siap kerja, atau menciptakan lapangan kerja baru (Faiz, 2021).

Proses pembelajaran dalam Kampus Merdeka merupakan salah satu perwujudan pembelajaran yang berpusat pada mahasiswa (student centred learning) yang sangat esensial. Pembelajaran dalam Kampus Merdeka memberikan tantangan dan kesempatan untuk pengembangan inovasi, kreativitas, kapasitas, kepribadian, dan kebutuhan mahasiswa, serta mengembangkan kemandirian dalam mencari dan menemukan pengetahuan melalui kenyataan dan dinamika lapangan seperti persyaratan kemampuan, permasalahan riil, interaksi sosial, kolaborasi, manajemen diri, tuntutan kinerja, target dan pencapaian nya (Aini, 2021). Melalui program merdeka belajar yang dirancang dan diimplementasikan dengan baik, maka hard dan soft skills mahasiswa akan terbentuk dengan kuat. Program Merdeka Belajar - Kampus Merdeka diharapkan dapat menjawab tantangan Perguruan Tinggi untuk menghasilkan lulusan yang sesuai perkembangan zaman, kemajuan IPTEK, tuntutan dunia usaha dan dunia industri, maupun dinamika masyarakat.

Untuk mendukung keberlangsungan program tersebut, pemerintah merancang sebuah portal resmi yang mengakomodir digitalisasi seluruh kegiatan kampus merdeka. Portal tersebut dapat diakses oleh seluruh peserta MBKM mulai dari mahasiswa, dosen serta Universitas. Sistem tersebut merupakan satu pintu informasi berkaitan dengan kebijakan kampus merdeka, juga untuk mengakomodir digitalisasi kegiatan yang dilakukan oleh seluruh peserta dari seluruh Perguruan Tinggi di Indonesia. Sistem tersebut disajikan dalam bentuk situs resmi yang mudah diakses oleh siapa pun.

Berbagai artikel dan jurnal telah membahas tentang konsep MBKM, relevansi nya, metode pelaksanaan dan evaluasi pelaksanaannya, namun penelitian yang membahas tentang efektivitas sistem pendukung kegiatan MBKM itu sendiri belum ditemukan. Sedangkan untuk keberlangsungan sebuah sistem dan efektivitas penggunaannya, sangat diperlukan analisis untuk dapat dijadikan acuan pengembangan lebih lanjut. Oleh karena itu penelitian ini mengintegrasikan sebuah model untuk menganalisis efektivitas portal resmi MBKM.

Penelitian ini mengadopsi model penelitian yang diusulkan oleh Delone \& McLean, Model Sukses Sistem Informasi (Seta \& Wati, 2018). Model ini mengidentifikasi pemahaman keseluruhan melalui keberhasilan implementasi Sistem Informasi (Ojo, 2017). Identifikasi tersebut meliputi enam dimensi keberhasilan. Keenam dimensi ini menguraikan beberapa faktor pada sistem portal resmi kampus merdeka. Dimensi tersebut dapat menggambarkan dengan jelas faktor keberhasilan dan efektivitas pengembangan portal resmi kampus merdeka. Dengan demikian, model ini dapat dengan baik menggambarkan determinan kinerja sistem (Trihandayani, et al., 2018)

Kesulitan penilaian keefektivan sebuah sistem mendorong banyak peneliti mengembangkan model untuk menilai kesuksesan sebuah sistem. Penelitian ini mengadopsi komponen-komponen yang ada pada model kesuksesan sistem informasi yaitu information quality, System quality, service quality, use, user satisfaction dan net benefit untuk dijadikan model awal untuk mengukur sejauh mana keefektivan aplikasi dalam mempermudah penumpang dalam hal bertransformasi dan mempengaruhi kesuksesan dan kegagalannya agar dapat dievaluasi untuk pengembangan dan perbaikan selanjutnya (Hidayatulloh, 2020).

Penelitian ini bertujuan untuk membuktikan bahwa model yang dikembangkan dapat digunakan untuk menguji keefektivan sistem portal resmi kampus merdeka dan juga untuk membentuk usulan hipotesis dan juga usulan kuesioner yang diharapkan dapat digunakan sebagai acuan untuk penelitian-penelitian selanjutnya. Penelitian ini dilakukan untuk menguji apakah kualitas sistem dan beberapa variabel lainnya berpengaruh terhadap keefektivan sebuah teknologi dan informasi baru. Penelitian ini juga diharapkan dapat memberikan hasil yang empiris pada literatur informasi.

\section{RUANG LINGKUP}

Ruang lingkup penelitian ini adalah penerapan model kesuksesan sistem informasi yang dikemukakan oleh DeLone and McLean pada studi kasus penggunaan sistem MBKM yang berupa portal resmi kampus merdeka. Permasalahan yang dibahas pada penelitian ini antara lain:

1. Menerapkan model Delone and Mclean sebagai model analisis efektivitas penggunaan portal resmi kampus merdeka.

2. Mengidentifikasi faktor-faktor yang berpengaruh terhadap penggunaan portal kampus merdeka.

3. Mengetahui hasil efektivitas kegunaan portal resmi kampus merdeka dari sisi pengguna.

\section{BAHAN DAN METODE}

Bagian ini menjelaskan bahan dan instrumen yang dipakai dalam penelitian, serta menjelaskan metode yang digunakan dalam penelitian ini, diantaranya:

\subsection{Populasi dan Sampel}

Dari model yang telah dikembangkan, penelitian ini menghimpun data dari populasi mahasiswa, dosen dan Perguruan Tinggi peserta MBKM. Lalu dari populasi yang ditetapkan, ditentukan sampel berupa mahasiswa dan dosen peserta MBKM, serta pihak-pihak yang terlibat dalam kegiatan MBKM di kampus Universitas Esa Unggul Jakarta. Penelitian ini menggunakan 
kuesioner yang disebarkan secara online. Dengan responden sebanyak 136 orang. Kuesioner ini berisi beberapa pertanyaan umum dan pertanyaan tertutup, dengan total pertanyaan pada kuesioner ini adalah sebanyak 23 (dua puluh tiga).

\subsection{Model DeLone and McLean}

Beberapa model untuk mengukur tingkat kesuksesan sistem informasi telah dikembangkan oleh banyak peneliti. Dari beberapa model kesuksesan sistem informasi, yang mendapat perhatian lebih dari para peneliti adalah model DeLone and McLean, yang selanjutnya disempurnakan menjadi Delone and Mclean Models. Delone and Mclean Models menyebutkan bahwa information quality, system quality dan service quality akan berpengaruh positif pada use dan user satisfaction dan selanjutnya akan berpengaruh positif pada net benefit atau hasil akhir, penelitian tersebut didukung pada penelitian yang dilakukan oleh Azizah dkk., yang menguji secara empiris model DeLone dan McLean tersebut. Hasil yang didapat membuktikan bahwa kesuksesan sistem informasi dipengaruhi oleh kualitas sistem, kualitas informasi dan kualitas layanan yang dihasilkan dari sistem yang bersangkutan (Azizah, et al., 2020). Model DeLone dan McLean yang digunakan pada penelitian ini yang dapat dilihat pada gambar 1 memberikan gambaran variabel-variabel yang menentukan efektivitas dan keberhasilan sebuah sistem. Model ini memuat 6 (enam) variabel yang saling terhubung dan memiliki indikator di dalamnya. Penelitian terhadap efektivitas portal resmi kampus merdeka ini menggunakan model pada gambar 1 yang telah disempurnakan variabel nya sesuai dengan relevansi sistem kampus merdeka.

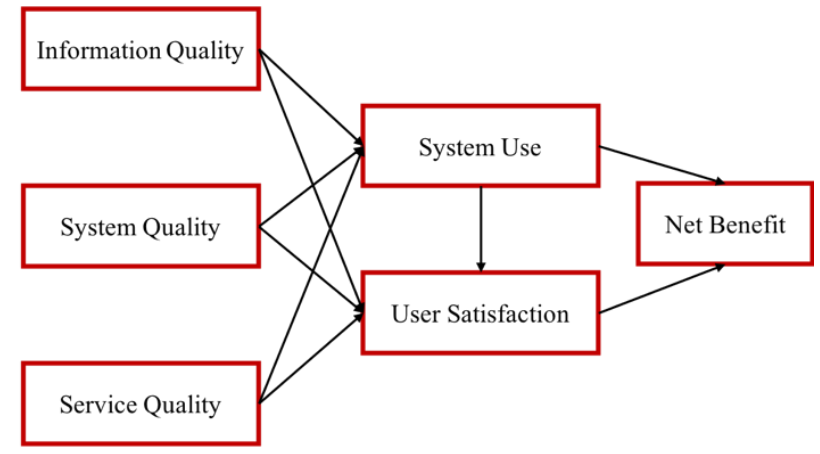

Gambar 1. Model DeLone and McLean

(Azizah, et al., 2020)

\subsection{Variabel Penelitian}

Pada penelitian ini, model yang kami gunakan adalah Information System Success Model. Variabel yang digunakan di sini adalah sesuai dengan usulan hipotesis dan juga yang ada pada model DeLone and McLean, selanjutnya dari variabel tersebut dicari indikatorindikator yang berpengaruh terhadap variabel tersebut.
Penjabaran terkait masing-masing variabel adalah (Alzahrani, 2017):

1. Kualitas Informasi (Information Quality). Kualitas informasi mengukur kualitas keluaran dari sistem informasi. Sama halnya dengan kualitas sistem, kualitas informasi yang dimaksud adalah kualitas informasi yang diukur secara subjektif oleh pemakai yang selanjutnya disebut sebagai kualitas informasi persepsi (perceived information quality). Pengukuran menggunakan lima skala pengukuran yaitu kelengkapan (completeness), ketepatan (precision), keandalan (reliability), data selalu diperbaharui (currency), dan bentuk dari keluaran (format of output) (Jaafreh, 2017) .

2. Kualitas Sistem (System Quality). Kualitas sistem digunakan untuk mengukur kualitas informasi sistem itu sendiri, baik software maupun hardware. Kualitas sistem adalah performa dari sistem yang merujuk pada seberapa baik kemampuan perangkat keras, perangkat lunak, kebijakan, prosedur dari sistem informasi dapat menyediakan informasi kebutuhan pengguna. Kualitas sistem diukur secara subjektif oleh pemakai, sehingga kualitas sistem yang digunakan adalah kualitas sistem persepsian (perceived system quality). Indikator yang digunakan terdiri atas enam skala pengukuran yakni: fleksibilitas sistem (system flexibility), integrasi sistem (system integration), waktu respond (time to respond), perbaikan kesalahan (error recovery), kenyamanan akses (convenience of access), dan bahasa (language).

3. Kualitas Layanan (Service Quality). Kualitas layanan sebagai sebuah perbandingan dari harapan pelanggan dengan persepsi dari layanan nyata yang mereka terima. Terdapat tiga komponen yang mempengaruhi dari kualitas layanan (service quality) yaitu jaminan (assurance) yaitu jaminan kualitas yang diberikan sistem, empati (system empathy) yaitu kepedulian sistem terhadap pengguna, system responsiveness yaitu kualitas respond sistem terhadap aksi yang dilakukan oleh pengguna.

4. Penggunaan (Use). Dilakukan pembedaan penggunaan (use) ke dalam penggunaan keluaran (information use) dan penggunaan sistem (system use) yang berarti penggunaan informasi dan penggunaan dari sistem informasi itu sendiri. Penelitian ini menggunakan dua item yaitu penggunaan waktu harian (daily used time) dan frekuensi penggunaan (frequency of use) yang dimaksud frekuensi penggunaan adalah frekuensi penggunaan sistem selama bekerja.

5. Kepuasan Pengguna (User Satisfaction). Kepuasan pemakai sistem (user satisfaction) merupakan respond dan umpan balik yang dimunculkan pengguna setelah memakai sistem informasi. Sikap pengguna terhadap sistem informasi merupakan kriteria subjektif mengenai seberapa suka pengguna 
terhadap sistem yang digunakan. Mengadopsi dari DeLone and McLean (2003) penelitian ini menggunakan dua item yaitu (Riasti \& Nugroho, 2019):

1) Kepuasan Informasi (Repeat Use). Perbedaan antara informasi yang dibutuhkan serta informasi yang diterima. "Secara umum kepuasan informasi sebagai hasil perbandingan pengharapan atau kebutuhan sistem informasi dengan kinerja sistem yang diterima".

2) Kepuasan Menyeluruh (Repeat Visit). Salah satu bentuk kepuasan secara global atas semua sistem yang sudah disajikan dan dilakukan interaksi mengenai tingkat kepuasan layanan informasi dan sistem. Serta manfaat dalam proses input proses output yang diterima.

6. Hasil bersih yang Didapat (Net Benefit). Net benefit adalah hasil bersih atau keuntungan yang dirasakan oleh individu dan juga organisasi setelah menerapkan sistem informasi. Penelitian ini menggunakan lima dari enam item yang diadaptasi dari ukuran persepsi kegunaan (perceived usefulness) yakni: speed of accomplishing task, job performance, effectiveness, ease of job, dan usefulness in work (Nugraheni \& Bayastura, 2021).

\subsection{Hipotesis}

Berdasarkan model DeLone and McLean yang diterapkan, hipotesis yang tersusun adalah:

H1a. Kualitas sistem (system quality) akan berpengaruh positif dan signifikan terhadap penggunaan (use);

H1b. Kualitas sistem (system quality) akan berpengaruh positif dan signifikan terhadap kepuasan pengguna (user satisfaction);

H2a. Kualitas informasi (information system) akan berpengaruh positif dan signifikan terhadap penggunaan sistem (use);

$\mathrm{H} 2 \mathrm{~b}$. Kualitas informasi (information system) akan berpengaruh positif dan signifikan terhadap kepuasan pengguna (user satisfaction);

H3a. Kualitas pelayanan (service quality) akan berpengaruh positif dan signifikan terhadap penggunaan sistem (use);

H3b. Kualitas pelayanan (service quality) akan berpengaruh positif dan signifikan terhadap kepuasan pengguna (user satisfaction);

H4. Penggunaan sistem (use) akan berpengaruh positif dan signifikan terhadap kepuasan pengguna (user satisfaction);

H5. Penggunaan sistem (use) akan berpengaruh positif dan signifikan terhadap hasil bersih yang didapatkan (net benefit);

H6. Kepuasan pengguna (user satisfaction) akan berpengaruh positif dan signifikan terhadap hasil bersih yang didapatkan (net benefit);

\subsection{Pengembangan Indikator}

Variabel yang terdapat pada model yang diusulkan selanjutnya dijabarkan ke dalam indikator, yang mana indikator ini merupakan hal yang terukur agar dapat dilakukan pengujian kuantitatif terhadap data. Indikator yang dibentuk dalam penelitian ini berdasar pada model kesuksesan sistem informasi dan beberapa penelitian sebelumnya (Zhu, et al., 2021). Masing-masing variabel memiliki 2 (dua) hingga 5 (lima) indikator seperti terlihat pada tabel 1, indikator ini yang akan menjelaskan arti dari variabel sehingga hipotesis yang dibangun dapat terukur (Azizah, et al., 2020).

Tabel 1. Pengembangan Indikator Penelitian

\begin{tabular}{|c|c|c|}
\hline No & Variabel & Indikator \\
\hline \multirow{5}{*}{1} & \multirow{5}{*}{ Information quality } & Completeness \\
\hline & & Precision \\
\hline & & Reliability \\
\hline & & Currency \\
\hline & & Format of Output \\
\hline \multirow{6}{*}{2} & \multirow{6}{*}{ System Quality } & System Flexibility \\
\hline & & System Integration \\
\hline & & Time To Respond \\
\hline & & Error Recovery \\
\hline & & Convenience of Access \\
\hline & & Language \\
\hline \multirow{3}{*}{3} & \multirow{3}{*}{ Service Quality } & Assurance \\
\hline & & System Empathy \\
\hline & & System Responsiveness \\
\hline \multirow{2}{*}{4} & \multirow{2}{*}{ System Use } & Daily Used Time \\
\hline & & Frequency of Use \\
\hline \multirow{2}{*}{5} & \multirow{2}{*}{ User Satisfaction } & Repeat Use \\
\hline & & Repeat Visit \\
\hline \multirow{5}{*}{6} & \multirow{5}{*}{ Net Benefit } & Speed of Accomplishing Task \\
\hline & & Job Performance \\
\hline & & Effectiveness \\
\hline & & Ease of Job \\
\hline & & Usefulness in Work \\
\hline
\end{tabular}

\subsection{Pembentukan Pertanyaan}

Pertanyaan dalam kuesioner yang terbentuk dari indikator-indikator variabel berjumlah 23 buah. Pertanyaan dalam kuesioner diambil dari referensi terkait dengan menyesuaikan kalimat dan kebutuhan penelitian (Lubis, et al., 2019).

Daftar pertanyaan ini yang kemudian disusun menjadi kuesioner dan kemudian disebarkan kepada seluruh responden untuk mendapatkan data primer berkaitan dengan penggunaan portal resmi kampus merdeka. Daftar pertanyaan yang dikembangkan dari indikator penelitian tertulis pada tabel 2, yang berupa pertanyaan tertutup.

\section{PEMBAHASAN}

Bagian ini menjelaskan hasil dari analisis data menggunakan instrumen yang telah dirancang. Pada bab ini juga menjabarkan hasil pengujian-pengujian terhadap model penelitian seperti pengujian instrumen survei, 
reliabilitas data, pengujian statistika deskriptif dan pengujian hipotesis.

\subsection{Rangkuman Responden}

Penelitian ini menggunakan pengembangan kuesioner tertutup yang disebarkan secara daring kepada pengguna. Item dalam variabel diukur menggunakan skala Likert 5 poin. Dengan deskripsi masing-masing poin yaitu angka 1 memiliki arti "Sangat Tidak Setuju", angka 2 memiliki arti "Tidak Setuju", angka 3 memiliki arti "Netral", angka 4 memiliki arti "Setuju", poin 5 memiliki arti "Sangat Setuju". Pemilihan skala likert ini didasarkan bahwa skala ini dapat mengungkapkan intensitas sikap atau perilaku responden. Indikator-indikator yang digunakan dalam instrumen penelitian ini merupakan adopsi dari penelitian-penelitian sebelumnya (Anfina, et al., 2018). Penelitian ini dikembangkan dengan metode kuantitatif dengan melibatkan sejumlah 136 responden, dengan komposisi terdiri dari mahasiswa, dosen dan pengguna sistem dari pihak Universitas, seperti yang terlihat pada gambar 2 status responden.

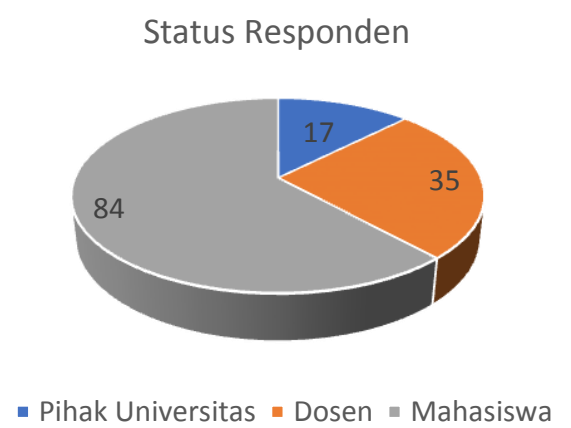

Gambar 2. Rangkuman status responden

Tabel 2. Pengembangan Pertanyaan Kuesioner

\begin{tabular}{|c|c|c|}
\hline No & Indikator & Pertanyaan \\
\hline 1 & Completeness & $\begin{array}{l}\text { Apakah portal resmi MBKM } \\
\text { menampilkan data yang lengkap? }\end{array}$ \\
\hline 2 & Precision & $\begin{array}{l}\text { Apakah informasi yang anda } \\
\text { dapatkan sesuai? }\end{array}$ \\
\hline 3 & Reliability & $\begin{array}{l}\text { Apakah data yang anda dapatkan } \\
\text { terpercaya? }\end{array}$ \\
\hline 4 & Currency & $\begin{array}{l}\text { Apakah data yang anda dapatkan } \\
\text { adalah informasi terkini? }\end{array}$ \\
\hline 5 & $\begin{array}{l}\text { Format } \text { Of } \\
\text { Output }\end{array}$ & $\begin{array}{l}\text { Apakah data yang anda dapatkan } \\
\text { dapat digunakan/dibuka pada } \\
\text { media lain? }\end{array}$ \\
\hline 6 & $\begin{array}{l}\text { System } \\
\text { Flexibility }\end{array}$ & $\begin{array}{l}\text { Apakah portal dapat diakses } \\
\text { sesuai kebutuhan? }\end{array}$ \\
\hline 7 & $\begin{array}{l}\text { System } \\
\text { Integration }\end{array}$ & $\begin{array}{l}\text { Apakah portal MBKM } \\
\text { terintegrasi dengan baik? }\end{array}$ \\
\hline 8 & $\begin{array}{l}\text { Time To } \\
\text { Respond }\end{array}$ & $\begin{array}{l}\text { Apakah waktu yang dibutuhkan } \\
\text { untuk mengakses portal MBKM } \\
\text { cukup singkat? }\end{array}$ \\
\hline 9 & Error Recovery & $\begin{array}{l}\text { Apakah sistem telah } \\
\text { memfasilitasi jika terjadi } \\
\text { error/kegagalan sistem? }\end{array}$ \\
\hline
\end{tabular}

\begin{tabular}{|c|l|l|}
\hline No & \multicolumn{1}{|c|}{ Indikator } & Pertanyaan \\
\hline 10 & $\begin{array}{l}\text { Convenience Of } \\
\text { Access }\end{array}$ & $\begin{array}{l}\text { Apakah anda merasa mudah dan } \\
\text { nyaman dalam menggunakan } \\
\text { sistem portal MBKM? }\end{array}$ \\
\hline 11 & Language & $\begin{array}{l}\text { Apakah bahasa dalam sistem } \\
\text { mudah dipahami? }\end{array}$ \\
\hline 12 & Assurance & $\begin{array}{l}\text { Apakah data yang anda upload } \\
\text { terjamin keamanannya? }\end{array}$ \\
\hline 13 & System Empathy & $\begin{array}{l}\text { Apakah sistem dapat memberikan } \\
\text { masukan baik? }\end{array}$ \\
\hline 14 & $\begin{array}{l}\text { System } \\
\text { Responsiveness }\end{array}$ & $\begin{array}{l}\text { Apakah sistem dapat memberikan } \\
\text { tanggapan terhadap perlakuan } \\
\text { pengguna? }\end{array}$ \\
\hline 15 & Daily Used Time & $\begin{array}{l}\text { Dalam sekali akses berapa lama } \\
\text { anda mengakses? }\end{array}$ \\
\hline 16 & $\begin{array}{l}\text { Frequency Of } \\
\text { Use }\end{array}$ & $\begin{array}{l}\text { Berapa kali anda mengakses } \\
\text { portal tersebut? }\end{array}$ \\
\hline 17 & Repeat Use & $\begin{array}{l}\text { Apakah anda akan menggunakan } \\
\text { ulang portal MBKM? }\end{array}$ \\
\hline 18 & Repeat Visit & $\begin{array}{l}\text { Apakah anda akan mengakses } \\
\text { ulang portal MBKM? }\end{array}$ \\
\hline 19 & $\begin{array}{l}\text { Speed Of } \\
\text { Accomplishing } \\
\text { Task }\end{array}$ & $\begin{array}{l}\text { Apakah sistem dapat memberikan } \\
\text { informasi dengan cepat? }\end{array}$ \\
\hline 20 & Job Performance & $\begin{array}{l}\text { Apakah dengan adanya portal ini } \\
\text { dapat mendukung pekerjaan } \\
\text { anda? }\end{array}$ \\
\hline 21 & $\begin{array}{l}\text { Apakah keefektivan meningkat } \\
\text { dengan menggunakan sistem ini? }\end{array}$ \\
\hline 22 & $\begin{array}{l}\text { Apakah dengan adanya portal ini } \\
\text { dapat memudahkan pekerjaan } \\
\text { anda? }\end{array}$ \\
\hline Ease Of Job & $\begin{array}{l}\text { Apakah portal MBKM ini } \\
\text { bermanfaat dalam kegiatan } \\
\text { MBKM? }\end{array}$ \\
\hline Work & & \\
\hline
\end{tabular}

\subsection{Statistika Deskriptif}

Proses perhitungan statistika deskriptif diperoleh menggunakan perangkat lunak SmartPLS. Analisis statistika deskriptif yang terlihat pada tabel 3, melakukan identifikasi nilai rata-rata (Mean), nilai tengah (Median), simpangan baku (Standard Deviation), derajat keruncingan (kurtosis) dan derajat kemiringan (skewness).

Skewness adalah derajat penyebaran suatu distribusi atau kemiringan. Jika kurva frekuensi suatu distribusi mempunyai ekor yang memanjang ke kanan maka dikatakan miring ke kanan (positif), dan jika sebaliknya mencuat ke kiri (negatif). Sedangkan kurtosis adalah derajat distorsi suatu distribusi. Kurva yang lebih runcing dari distribusi normal disebut leptokurtik, yaitu platikurtik yang lebih datar dan distribusi normal yang disebut mesokurtik. Pengukuran lain yang dinilai adalah mean dan standar deviasi. Dari hasil yang ditunjukkan pada tabel 3, standar deviasi menunjukkan bahwa ukuran dispersi atau variasi cukup mirip. 

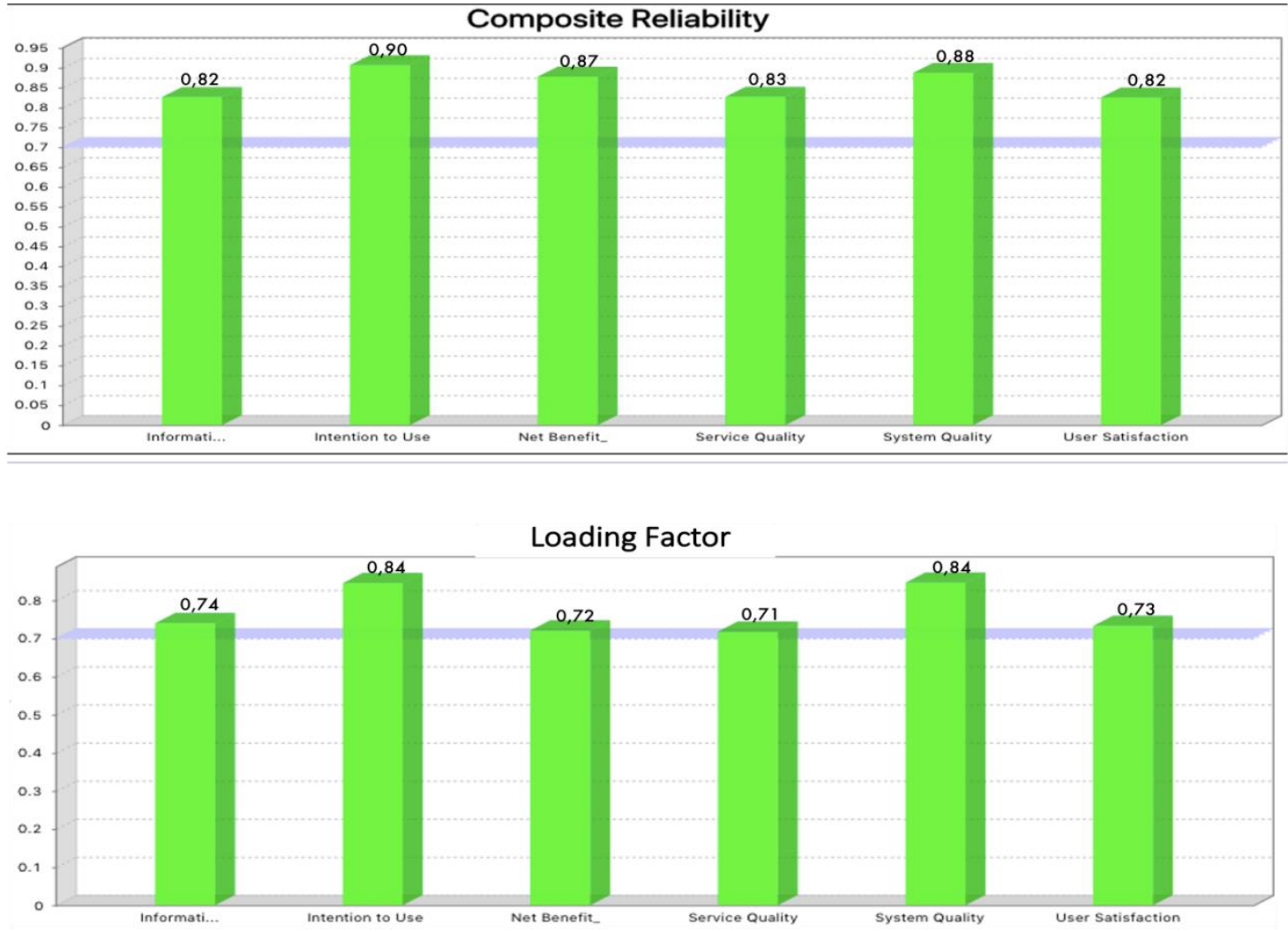

Gambar 3. Uji Reliabilitas dan Validitas

\subsection{Pengujian Instrumen Model}

Pengujian terhadap instrumen model dilakukan dengan mengetahui reliabilitas serta validitas komponen instrumen. Reliabilitas dapat didefinisikan sebagai kepercayaan, keandalan, atau konsistensi. Hasil suatu pengukuran dapat dipercaya jika dalam beberapa kali pengukuran terhadap subjek yang sama diperoleh hasil yang relatif sama, artinya memiliki konsistensi pengukuran yang baik.

Composite Reliability adalah metode untuk mengukur keandalan konsistensi internal beberapa skala item. Uji reliabilitas dapat dilihat dari nilai cronbach's alpha dan nilai reliabilitas komposit. Untuk dapat dikatakan suatu konstruksi reliabel, maka nilai Composite reliability harus $>0,7$ (Sorongan, 2020).

Sedangkan validitas data dapat diketahui dengan melakukan pengujian convergent validity. Convergent Validity dilakukan dengan melihat item reliability (indikator validitas) yang ditunjukkan oleh nilai loading factor. Loading factor adalah angka yang menunjukkan korelasi antara skor suatu item pertanyaan dengan skor indikator konstrak indikator yang mengukur konstrak tersebut. Nilai loading factor lebih besar 0,7 dikatakan valid. Hasil pengujian reliabilitas dan validitas yang terlihat pada gambar 3 menunjukkan bahwa seluruh instrumen model penelitian valid dan reliabel.
Tabel 3. Statistika Deskriptif

\begin{tabular}{|l|l|l|l|l|l|}
\hline $\begin{array}{l}\text { Kode } \\
\text { Indikator }\end{array}$ & Mean & Median & SD & Kurtosis & Skewness \\
\hline KI1 & 3,641 & 4.000 & 0,715 & $-0,787$ & 0,688 \\
\hline KI2 & 3,609 & 4.000 & 0,628 & $-0,590$ & 0,542 \\
\hline KI3 & 3,578 & 4.000 & 0,607 & $-0,571$ & 0,549 \\
\hline KI4 & 3,672 & 4.000 & 0,588 & $-0,604$ & 0,238 \\
\hline KI5 & 3,453 & 3.000 & 0,584 & $-0,127$ & 0,908 \\
\hline KL1 & 3,375 & 3.000 & 0,545 & 0,274 & 1,113 \\
\hline KL2 & 3,859 & 4.000 & 0,704 & $-0,962$ & 0,209 \\
\hline KL3 & 3,641 & 4.000 & 0,670 & $-0,680$ & 0,582 \\
\hline KS1 & 3,578 & 4.000 & 0,581 & $-0,686$ & 0,420 \\
\hline KS2 & 3,782 & 4.000 & 0,754 & $-0,604$ & 0,513 \\
\hline KS3 & 3,564 & 3.000 & 0,812 & $-0,560$ & 0,469 \\
\hline KS4 & 3,112 & 4.000 & 0,652 & $-0,516$ & 0,561 \\
\hline KS5 & 3,287 & 3.000 & 0,517 & $-0,342$ & 0,539 \\
\hline KS6 & 3,809 & 3.000 & 0,719 & $-0,562$ & 1,012 \\
\hline P1 & 3,971 & 4.000 & 0,589 & $-0,712$ & 0,418 \\
\hline P2 & 3,239 & 4.000 & 0,667 & $-0,604$ & 0,329 \\
\hline P3 & 3,656 & 4.000 & 0,651 & $-0,423$ & 0,446 \\
\hline P4 & 3,674 & 4.000 & 0,871 & $-0,511$ & 0,399 \\
\hline H1 & 3,734 & 4.000 & 0,619 & $-0,575$ & 0,251 \\
\hline H2 & 3,641 & 4.000 & 0,596 & $-0,634$ & 0,339 \\
\hline H3 & 3,719 & 4.000 & 0,649 & $-0,691$ & 0,361 \\
\hline H4 & 3,781 & 4.000 & 0,717 & $-0,999$ & 0,359 \\
\hline H5 & 3,594 & 4.000 & 0,630 & $-0,560$ & 0,593 \\
\hline
\end{tabular}




\subsection{Hasil Uji Hipotesis}

Pengujian hipotesis adalah proses pengambilan keputusan dimana peneliti mengevaluasi hasil penelitian tentang apa yang ingin dicapai sebelumnya. Penelitian ini bertujuan untuk menguji apakah variabel kualitas informasi, kualitas sistem, dan kualitas layanan berpengaruh terhadap niat penggunaan dan kepuasan pengguna serta apakah niat penggunaan dan kepuasan pengguna berpengaruh terhadap efektivitas sistem. Semakin tinggi nilai $\mathrm{R}$-square berarti semakin baik model prediksi dari model penelitian yang diajukan. Gambar 4 menampilkan hasil pengujian hipotesis terhadap 6 (enam) variabel pada model DeLone and McLean.

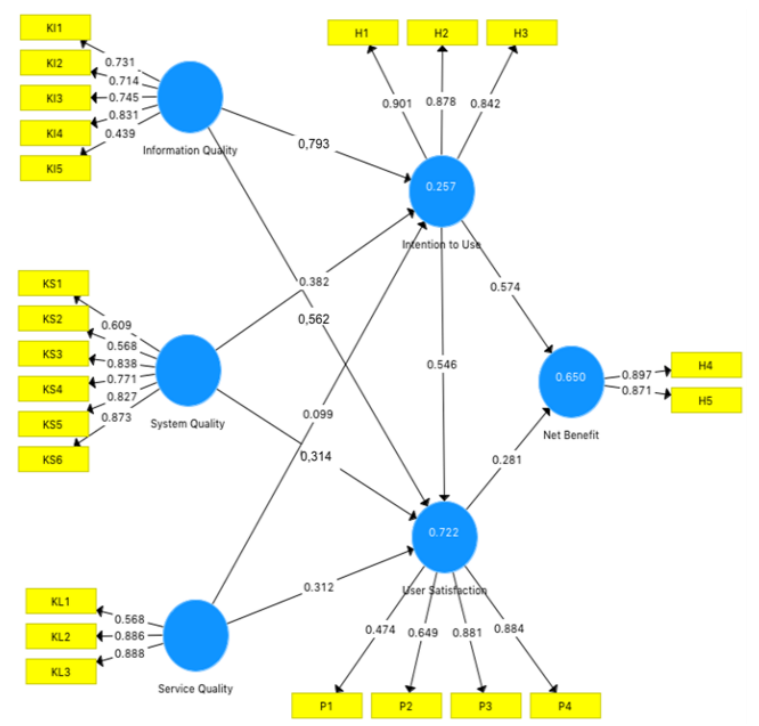

Gambar 4. Hasil pengujian hipotesis

Dari keseluruhan hipotesis yang dirancang, delapan hipotesis diterima dan menyatakan pengaruh signifikan pada model yang diteliti, serta hanya terdapat satu hipotesis yang menyatakan tidak berpengaruh signifikan, yakni kualitas layanan terhadap niat untuk menggunakan. Hal ini dapat diartikan bahwa minat pengguna untuk mengadopsi portal resmi kampus merdeka cukup besar dan efektivitas masih dapat dikembangkan lagi.

\section{KESIMPULAN}

Model DeLone and McLean merupakan sebuah model kesuksesan sistem informasi yang dapat diterapkan untuk melakukan analisis efektivitas pada implementasi portal resmi kampus merdeka. Dari hasil analisis data statistik dengan mengeksekusi instrumen penelitian yang telah teruji valid dan reliabel, didapatkan hasil bahwa sebagian besar hipotesis diterima, hanya terdapat satu hipotesis yang ditolak yaitu kualitas layanan terhadap niat untuk menggunakan.

Variabel atau faktor-faktor yang mempengaruhi efektivitas penggunaan sistem yaitu kualitas informasi, kualitas sistem dan kualitas layanan diketahui memberikan dampak signifikan terhadap niat untuk menggunakan dan kepuasan pengguna. Kemudian dari variabel tersebut mempengaruhi keuntungan penggunaan sistem.

Sistem portal resmi kampus merdeka terbukti efektiv dalam memberikan informasi terkini dan akomodir digitalisasi kegiatan MBKM pada Perguruan Tinggi seluruh Indonesia. Penelitian ini memberikan kontribusi terhadap pembentukan model analisis untuk melakukan analisis efektivitas portal resmi kampus merdeka, yang mana ke depan portal resmi ini akan menjadi pusat sistem kegiatan MBKM bagi mahasiswa, dosen maupun Perguruan Tinggi. Adanya model analisis ini dapat menjadi acuan untuk pengembangan sistem secara berkelanjutan.

\section{SARAN}

Saran terhadap penelitian ini adalah upaya untuk perluasan sampel agar dapat memberikan hasil data yang lebih beragam dan relevan sesuai dengan perkembangan program MBKM di Indonesia. Di samping itu, penambahan variabel lain dari model sejenis dari penelitian-penelitian sebelumnya juga dapat memberikan hasil yang lebih signifikan. Penelitian selanjutnya dapat juga melakukan integrasi dengan model lain, misalnya modelnya Task Technology Fit.

Pengembangan sistem informasi akan semakin cepat dari masa ke masa, model analisis yang telah diuji dan dapat menjadi rujukan juga tentu dapat dikembangkan sesuai dengan kebutuhan sistem dan akan memberikan dampak signifikan bagi efektivitas sistem informasi.

\section{DAFTAR PUSTAKA}

BK Prahani, U. A. D. M. Y. S. A. P. H. M., 2020. The Concept of "Kampus Merdeka" in Accordance withFreire's Critical Pedagogy. Studies in Philosophy of Science and Education (SiPoSE), 1(1), pp. 21-37.

Sudaryanto, W. W. R. A., 2020. Konsep Merdeka Belajar-Kampus Merdeka dan Aplikasinya dalam Pendidikan Bahasa (dan Sastra) Indonesia. Jurnal Bahasa, 9(2).

Nurhayani Siregar, R. S. A. A. H., 2020. Konsep Kampus Merdeka Belajar di Era Revolusi Industri 4.0. Fitrah: Journal of Islamic Education, 1(1).

Faiz, A., 2021. Koherensi Program Pertukaran Pelajar Kurikulum Merdeka Belajar Kampus Merdeka dan General Education. Jurnal Ilmu Pendidikan, 3(3).

Tuti Marjan Fuadi, D. A., 2021. Merdeka Belajar Kampus Merdeka (MBKM): Bagaimana Penerapan dan Kedala yang Dihadapi Oleh Perguruan Tinggi Swasta di Aceh. Jurnal Dedikasi Pendidikan, 5(2), pp. 603-614.

Aini, Q., 2021. Gamification-based The Kampus Merdeka Learning in 4.0 era. IJCCS (Indonesian Journal of Computing and Cybernetics Systems), 15(1). 
Theresia Wati, A. M. A. N. H. \& Seta, H. B., 2018. ELearning Success Model: An Extention of DeLone \& McLean IS' Success Model. Indonesian Journal of Electrical Engineering and Informatics (IJEEI), 6(3).

Ojo, A. I., 2017. Validation of the DeLone and McLean Information Systems Success Model. Healthcare Informatics Research, 23(1), pp. 60-66.

Trihandayani, L. H., Aknuranda, I. \& Mursityo, Y. . T., 2018. Penerapan Model Kesuksesan Delone dan Mclean pada Website Fakultas Ilmu Komputer (FILKOM) Universitas Brawijaya. Jurnal Pengembangan Teknologi Informasi dan Ilmu Komputer, 2(12).

Hidayatulloh, S., 2020. Implementasi Model Kesuksesan Sistem Informasi DeLone And McLean Terhadap Sistem Pembelajaran Berbasis Aplikasi Zoom Di Saat Pandemi Covid-19. Jurnal Teknologi dan Manajemen Informatika, 6(1).

Azizah, A. H. dkk., 2020. Factors affecting ERP (Enterprise Resource Planning) system adoption: A comparative analysis between SMEs and large companies. The Second International Symposium on Future Information and Communication Technology, 1(2).

Alzahrani, A. I., 2017. Modelling digital library success using the DeLone and McLean information system success model. Journal of Librarianship and Information Science, 51(2), pp. 291-306.

Jaafreh, a. B., 2017. Evaluation Information System Success: Applied DeLone and McLean Information System Success Model in Context Banking System in KSA. International Review of Management and Business Research, 6(2), pp. 829-845.

Riasti, B. K. \& Nugroho, A., 2019. Analysis of the Success of Student Monitoring Information System Implementation Using DeLone And McLean
Model. International Conference Computer Science and Engineering.

Nugraheni, D. M. K. \& Bayastura, S. F., 2021. Analysis of factors that influence satisfaction and usefulness for attendance system with the Delone \& McLean model (case study: attendance system at Diponegoro University). Journal of Physics: Conference Series, Volume 1943.

Zhu, Y.-q., Azizah, A. H. \& Hsiao, B., 2021. Examining multi-dimensional trust of technology in citizens' adoption of e-voting in developing countries. Information Development, 37(2), pp. 193-208.

Azizah, A. H., Fauzi, R. \& Alam, P. F., 2020. Discovering the Impact of ERP (Enterprise Resource Planning) Adoption toward Employee Performance. Proceedings of the First International Conference of Science, Engineering and Technology, p. 231.

Lubis, M., Witjaksono, R. W. \& Azizah, A. H., 2019. Implementation of Enterprise Resource Planning (ERP) using Integrated Model of Extended Technology Acceptance Model (TAM) 2. 7th International Conference on Cyber and IT Service Management (CITSM), Volume 7, pp. 1-6.

Anfina, A., Salisah, F. . N. \& Permana, I., 2018. Analisa Kesuksesan Penerapan Sistem Perhotelan Dengan Pendekatan Model Delone and Mclean. Jurnal Ilmiah Rekayasa dan Manajemen Sistem Informasi, 4(1), pp. 56-59.

Sorongan, E., 2020. Evaluation of Implementation EGovernment with Delone and Mclean. Jurnal Ilmiah Penelitian dan Penerapan Teknologi Sistem Informasi, 4(10). 